\title{
Shield Tunneling under Railway Station Throats in Soft Soil Areas: A Case Study
}

\author{
Chengyu Liu, ${ }^{1,2}$ Binglong Wang $\mathbb{D}^{1,2}$ and Shunhua Zhou ${ }^{1,2}$ \\ ${ }^{1}$ Shanghai Key Laboratory of Rail Infrastructure Durability and System Safety, Tongji University, Shanghai 201804, China \\ ${ }^{2}$ Key Laboratory of Road and Traffic Engineering of the Ministry of Education, Tongji University, Shanghai 201804, China \\ Correspondence should be addressed to Binglong Wang; wangbinglong6@163.com
}

Received 20 November 2019; Revised 16 July 2020; Accepted 20 August 2020; Published 8 September 2020

Academic Editor: Xuemei Liu

Copyright (c) 2020 Chengyu Liu et al. This is an open access article distributed under the Creative Commons Attribution License, which permits unrestricted use, distribution, and reproduction in any medium, provided the original work is properly cited.

Railway station throats have the most stringent standards for permissible deformation caused by adjacent construction. This paper describes the case of a safely implemented shield tunneling project beneath the throat of a large railway station with more than 11 tracks in soft soil areas. By identifying major design constraints, the route scheme and line alignment were established to balance the engineering conditions, which have a potential impact on the railway switches. Finite element model simulations were performed to estimate the track displacements. These simulations demonstrated the need for ground improvement. The ground improvement strategy involved the use of compact machinery to operate in the small area between the tracks. Furthermore, the earth-pressure-balanced shield machine, tunnel segments, and synchronized slurry were optimized to the site conditions. A trial section of tunnel boring was used before reaching the railway to confirm appropriate shield machine parameters. An automatic monitoring system provided continuous feedback for precise control of the construction parameters. Ultimately, the construction project achieved its goals, causing a maximum track displacement of $8.4 \mathrm{~mm}$. This report also describes our experience in organizing a joint workshop consisting of the railway administration and operation teams, the metro design team, and construction, survey, and consulting companies to enhance project planning. This study provides valuable insight and can serve as an important reference for similar future projects.

\section{Introduction}

With the expanding scale of urban rail transit construction in China, existing passenger railway stations are increasingly being used as metro line stations, resulting in underground complexities, as discussed in previous reports [1-3]. The shield tunneling method is commonly used in metro rail construction to excavate tunnels for the railway. To facilitate efficient passenger transfer in case of large passenger volumes, it is preferable for the metro station to be close to the passenger railway station, in which case, the metro railway tunnel will inevitably cross under the turnouts located in the passenger railway station throat.

The turnout is the area of the railway with the most stringent restrictions for settlement and deformation control. According to the Chinese Specifications on Railway Line Repair [4], the permissible deformation at the actual location of the switch rail after repair is $1 \mathrm{~mm}$. Moreover, the station throat is the constricted area at the end of a railway station connected by turnouts and crossing lines, and running lines divide into platform tracks at the station throat. Accordingly, this station area is critical for performing train and shunting operations, as well as facilitating the arrival and departure of passenger trains. Due to its sophisticated layout, heavy traffic, and the challenges associated with the adjustment, reconstruction, or expansion, the station throat is the most restrictive and influential area in defining the capacities of railway stations [5]. Therefore, the safety and functionality of the station throat must be preserved in adjacent construction projects.

Soft soil stratum further increases the difficulty of station expansion projects. In China, the distribution of soft soil is mostly coincident with economically developed areas, which prominently include the Yangtze River Delta Region. Shield 
tunnel construction in this area has been shown to cause ground surface settlement due to overexcavation and stress relief effects, as discussed in the literature [6-10], which affects the allowable geometry of railway lines. In addition to the challenges of controlling deformation at the switches, trainloads from multiple parallel tracks will be superimposed in the intersection area, which further increases the challenges of controlling deformation [11]. Huo et al. [1] described three shield tunneling projects conducted in Shanghai, which caused a $16.76-25.4 \mathrm{~mm}$ subsidence of the railway subgrade above the tunnel, even with grouting improvement. In cases with such pronounced subsidence, the functionality of the railway switches is not adequately protected. Therefore, it is necessary to analyze the impact of tunnel construction on the operation of overlying railways and to determine appropriate countermeasures to be taken during metro construction under an existing passenger railway station.

This paper presents a case study of ensuring safe implementation of shield tunneling for the construction of Shanghai Metro Line 15, which crosses beneath the turnout areas of Shanghai South Railway Station. Details are provided regarding the route scheme comparison, numerical simulation, design of the improvement range, improvement method selection, mechanical optimization, construction parameter control, and real-time monitoring feedback involved in this project, as well as the coordinated efforts of multiple project stakeholders. This article provides valuable insight into complex railway construction projects and will serve as an important reference for similar projects.

\section{Project Overview}

2.1. Project Information. Shanghai Metro Line 15 is the north-south radial metro line in the west of Shanghai [12]. The section between Shanghai South Railway Station and Baise Road Station passes through the station throat on the east side of Shanghai South Railway Station as well as the Liuzhou Road Interchange, crossing a total of 14 railway tracks and two subway tracks. The project consists of two single-track tunnels with $5.9 \mathrm{~m}$ inner diameters, $6.6 \mathrm{~m}$ outer diameters, and $350 \mathrm{~mm}$ thick reinforced concrete segmental lining.

Shanghai South Railway Station is shown in Figure 1; it has six platforms and 12 arrival and departure lines. The throat turnouts are densely arranged as they are restricted by the terrain, and some of the turnouts are double-slip turnouts. Currently, there are 36 pairs of Jinshan Railway electric multiple unit (EMU) trains, nine pairs of EMU trains that run along the Yangtze River, and 33 pairs of conventional passenger trains that depart southward. There are also 15 pairs of pass-through trains and 19 pairs of other trains, totaling 102 train pairs; 62,000 passengers are transferred on these trains per day.

2.2. Geological Conditions. The subgrade of the Shanghai South Railway Station throat, through which the section tunnel in this project passes, is a typical Shanghai soft soil layer, as described in [7]. The main soil layers are as follows: $1_{1}=$ miscellaneous fill, $1_{1-2}=$ plain fill, $2_{1}=$ silty clay, $3_{1}=$ silty clay, $4_{1-1}=$ silty clay, $5_{1-1}=$ silty clay mixed with silty soil, $5_{2}=$ medium-density silty sand, $6=$ clay, and $7_{1}=$ sandy silt. The groundwater table is $0.8-2.6 \mathrm{~m}$ below the surface. The $5_{2}$ layer exerts confining water pressure from 3.5 to $5.0 \mathrm{~m}$ below the surface, while the 7 layer exerts confining pressure from 5.9 to $10.0 \mathrm{~m}$ below the surface.

The shield machine mainly tunnels through the $5_{2}$ medium-density silty sand layer, which has a bearing capacity of $130 \mathrm{kPa}$. The machine is partially located in $5_{1-2}$, which is soft plastic silty clay with a bearing capacity of $80 \mathrm{kPa}$. The soil parameters are shown in Table 1.

\section{Details of Project Planning and Design}

3.1. Proposed Route Schemes and Optimal Determination. The comparison and selection of route design schemes is a critical and influential part of railway construction projects. Every scheme has its advantages and disadvantages, and these features lead to different design constraints and possible engineering outcomes. Therefore, this section describes the scheme comparison in two detailed stages: the routing scheme and line alignment design.

As shown in Figure 2, there were three potential route schemes, each corresponding to a different station location. These schemes include the initial scheme proposed in urban development planning, the west Guilin Road scheme, and the east Liuzhou Road scheme.

Two significant drawbacks led to the abandonment of the scheme initially proposed in urban development planning. First, the structures initially reserved for the metro line beneath the Shanghai South Railway Station were no longer suitable. During the construction of Shanghai South Railway Station, $80 \mathrm{~m}$ long dual-sided platforms and Double-O-Tube (DOT) tunnel sections were constructed to the north and south. The application of the DOT tunnel structure in Shanghai was introduced by Huang and Zeng [13] and Ren et al. [14]. However, these structures were designed for metro trains with four $2.4 \mathrm{~m}$ wide cars. This capacity is insufficient at the present urban scale; thus, the design of Metro Line 15 was expanded to use trains with six $3.0 \mathrm{~m}$ wide cars. This change rendered the originally reserved structures insufficient. Furthermore, reconstruction and expansion of the reserved structures would have had a significant negative impact on the operation of the existing underground passage in Shanghai South Railway Station and Metro Lines 1 and 3. Second, in the initial plan, the metro tunnel would have passed through 16 residential buildings on the north side of Shanghai South Railway Station. Due to rapidly increasing housing prices and the construction approval process in China, this plan would have caused increased environmental impacts and substantial financial pressure for resident compensation.

The route along Guilin Road on the west side of Shanghai South Railway Station has a shorter line length and straighter line shape. However, the transfer distance to Metro Lines 1 and 3 and Shanghai South Railway Station would have been approximately $700 \mathrm{~m}$, which would not have facilitated 


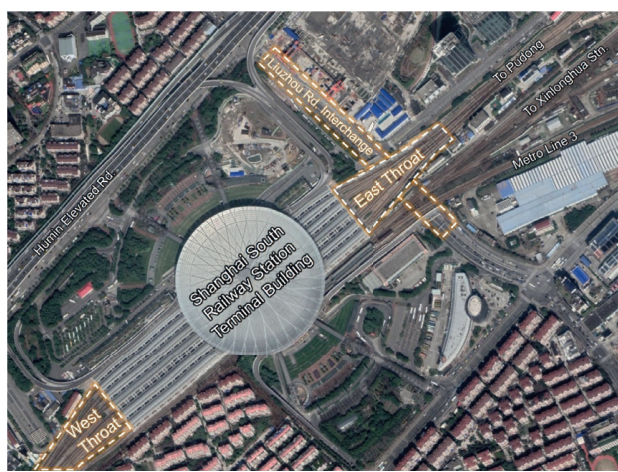

(a)

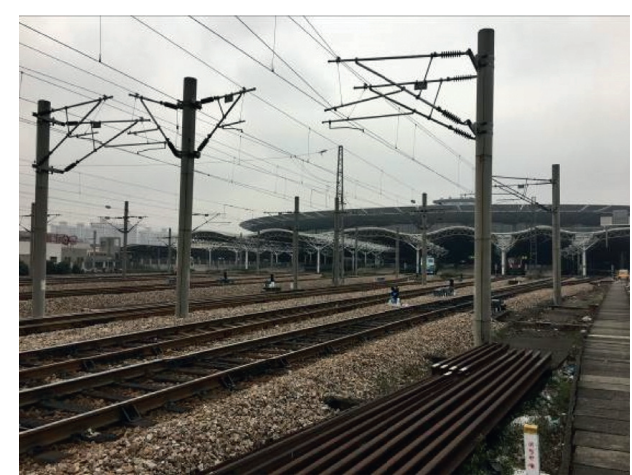

(b)

Figure 1: Shanghai South Railway Station. (a) Bird's-eye view. (b) Close up of the station's east throat.

TABLE 1: Soil parameters of the construction site.

\begin{tabular}{|c|c|c|c|c|c|c|c|c|c|c|}
\hline $\begin{array}{l}\text { Layer } \\
\text { index }\end{array}$ & $\begin{array}{c}\text { Geologic } \\
\text { origin }\end{array}$ & Classification & $\begin{array}{l}\text { Buried } \\
\text { depth } \\
(\mathrm{m})\end{array}$ & $\begin{array}{c}\text { Density, } \\
\rho \\
\left(\mathrm{g} / \mathrm{cm}^{3}\right)\end{array}$ & $\begin{array}{l}\text { Permeability, } \\
\text { vertical, } K_{V} \\
\quad(\mathrm{~cm} / \mathrm{s})\end{array}$ & $\begin{array}{c}\text { Permeability, } \\
\text { horizontal, } \\
K_{H}(\mathrm{~cm} / \mathrm{s})\end{array}$ & $\begin{array}{l}\text { Compression } \\
\text { modulus, } \\
E_{s 0.1-0.2}(\mathrm{MPa})\end{array}$ & $\begin{array}{c}\text { Cohesion, } \\
c(\mathrm{kPa}) \\
(\mathrm{CU} \text { test })\end{array}$ & $\begin{array}{l}\text { Friction } \\
\text { angle, } \varphi \\
\left({ }^{\circ}\right)(\mathrm{CU} \\
\text { test })\end{array}$ & $\begin{array}{c}\text { Basic } \\
\text { bearing } \\
\text { capacity, } \\
f_{a \mathrm{k}}(\mathrm{kPa})\end{array}$ \\
\hline $1_{1}$ & $\mathrm{Q}_{4}{ }^{3}$ & $\begin{array}{l}\text { Miscellaneous } \\
\text { fill }\end{array}$ & $1.2-6.2$ & - & - & - & & - & - & - \\
\hline $1_{1-2}$ & $\mathrm{Q}_{4}{ }^{3}$ & Plain fill & 0 & - & - & - & & - & - & - \\
\hline 21 & $\mathrm{Q}_{4}{ }^{3}$ & Silty clay & $0.5-3.0$ & 1.79 & $8.9 E-07$ & $1.33 E-06$ & 4.56 & 18 & 16.5 & 70 \\
\hline 3 & $\mathrm{Q}_{4}{ }^{2}$ & Soft silty clay & $5.1-9.3$ & 1.69 & $2.22 E-07$ & $3.2 E-07$ & 3.17 & 13 & 13.5 & 50 \\
\hline $4_{1}$ & $\mathrm{Q}_{4}{ }^{2}$ & Silty clay & $11.4-17.4$ & 1.66 & $1.95 E-07$ & $2.75 E-07$ & 2.07 & 13 & 11.5 & 50 \\
\hline $5_{1}$ & $\mathrm{Q}_{4}{ }^{1}$ & Clay & $14.5-25.4$ & 1.75 & $2.62 E-07$ & $1.9 E-07$ & 3.02 & 14 & 17.5 & 70 \\
\hline $5_{1-1}$ & $\mathrm{Q}_{4}{ }^{1}$ & Sandy silt & $18.3-21.5$ & 1.75 & $2.62 E-07$ & $1.9 E-07$ & 9.61 & 4 & 31 & 120 \\
\hline $5_{1-2}$ & $\mathrm{Q}_{4}{ }^{1}$ & Silty clay & $20.9-25.5$ & 1.78 & $1.63 E-06$ & $2.39 E-06$ & 3.37 & 15 & 16 & 80 \\
\hline $5_{2}$ & $\mathrm{Q}_{4}{ }^{1}$ & Silty sand & $17.1-21.8$ & 1.81 & $1.13 E-05$ & $1.76 E-05$ & 8.89 & 0 & 33.5 & 130 \\
\hline $5_{3-1}$ & $\mathrm{Q}_{4}{ }^{1}$ & Silty clay & $26-29.8$ & 1.79 & $1.7 E-06$ & $2.72 E-06$ & 4.35 & 21 & 19 & 100 \\
\hline 6 & $\mathrm{Q}_{3}{ }^{2}$ & Clay & $19.2-30.9$ & 1.92 & $2.88 E-07$ & $4.32 E-07$ & 6.82 & 45 & 16.5 & 130 \\
\hline $7_{1}$ & $\mathrm{Q}_{3}{ }^{2}$ & Sandy silt & $26.7-34.9$ & 1.90 & $3.2 E-04$ & $4.37 E-04$ & 11.41 & 10 & 31.3 & 150 \\
\hline
\end{tabular}

passenger interchange between lines. Moreover, the shield machine would have needed to cross through the buried tunnel section of Metro Line 1 and cut off its $38 \mathrm{~m}$ deep concrete diaphragm wall, posing significant engineering risks. Conversely, the proposed route along Liuzhou Road has more line curves, but it guarantees that the transfer distances to Metro Lines 1 and 3 as well as Shanghai South Railway Station would not exceed $300 \mathrm{~m}$. The metro station in this proposed route would also integrate well with the development of associated commercial plots with large floor-area ratios (FAR). Importantly, the proposed Guilin Road and Liuzhou Road schemes both pass through the station throat of Shanghai South Railway Station, and metro rail transit construction has a significant impact on railway operation. After comprehensive comparison of the proposed route schemes (Table 2), the Liuzhou Road scheme was selected due to its enhanced interchange and transfer functionality and the fact that the impacts of the project on the safety, operation, and organization of the passenger railway can be hedged with extensive engineering measures.

After the route scheme and station location were determined, the detailed line alignment schemes were compared. The terrain surrounding the eastern throat of Shanghai South Railway Station is complex and poses challenges to construction.

Figure 3 illustrates the numerous design and construction constraints in this project. The specific factors are as follows. First, the metro station to be built for Line 15 is an underground, three-story island station. The southern end of the station is $128 \mathrm{~m}$ from the railway, and the retaining piles were previously constructed. Second, the east throat of Shanghai South Railway Station is close to Liuzhou Road Interchange. The section of Liuzhou Road Interchange buried under the railway is a reinforced concrete frame structure, and the mixing piles under the bottom plate are approximately $13.5 \mathrm{~m}$ long. Furthermore, there is a retaining structure with $15 \mathrm{~m}$ long cement mixing piles, which was constructed for the foundation pit of the buried section of Liuzhou Road Interchange. The open section of the interchange on the north side of the railway is a U-shaped groove structure. Third, antifloating anchor rod piles are located under the bottom plate with a buried depth of approximately $18.5-21 \mathrm{~m}$. The ramp to the open section of the interchange is also very close to the building of the railway station; the pile 


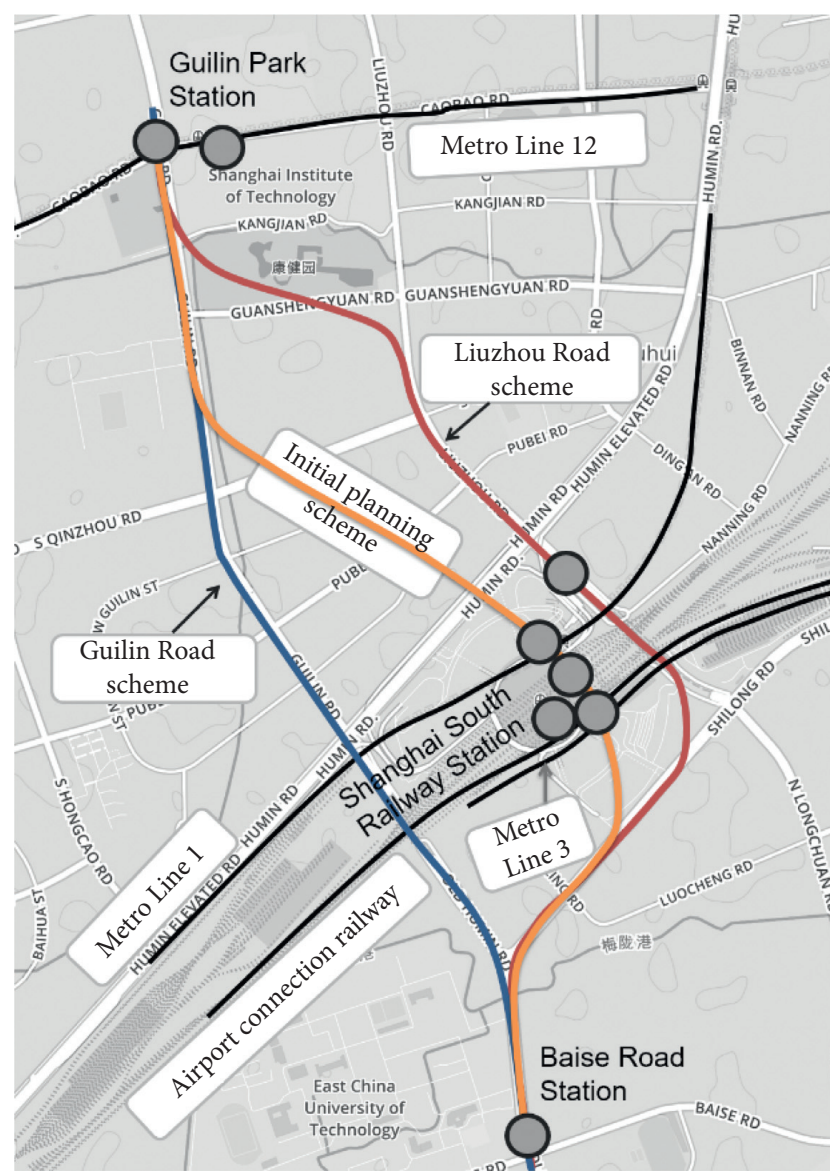

Figure 2: Plan view of the potential route schemes.

foundation of the ramp is approximately $44 \mathrm{~m}$ from the interchange. There were also reserved piles for future magnetic levitation train operations in Shanghai South Railway Station located approximately $20 \mathrm{~m}$ from Liuzhou Road Interchange. Finally, there are $21-34 \mathrm{~m}$ rigid pile foundations for the longdistance bus station, postal transfer station, and foundation pit of the south square of the train station.

The line alignment schemes were determined based on the minimum curve radius; Table 3 provides a detailed comparison. In alignment scheme 1 , the operating conditions of the subway are adequate, but there are numerous directly influenced railway turnouts. Furthermore, the tunnel section crossing the railway is curved, which is unfavorable for controlling the subsidence. In alignment schemes 2 and 3, there are fewer passenger rail turnouts above the metro line, and the spatial relationship between the transit line and railway turnouts in the two schemes is similar. Importantly, however, alignment scheme 3 involves small-radius curves for the metro line sections crossing the turnouts, which is unfavorable. Therefore, alignment scheme 2 was selected, as was a curve with a radius of $350 \mathrm{~m}$ to be used in the tunnels leaving the metro station for the interchange. A profile view of the alignment scheme is given in Figure 4.

3.2. Numerical Assessment of Ground Improvement. In order to analyze the influence of shield tunneling on the deformation of the railway subgrade and to assess the need for foundation improvement, the geotechnical finite element software PLAXIS 3D was used to create an integrated model including layered soil, tunnels, reinforcement bodies, subgrade, and railway tracks. The model had a total length of $230 \mathrm{~m}$, a total width of $190 \mathrm{~m}$, and a depth of approximately $70 \mathrm{~m}$ (Figure 5). Boundary conditions were set as follows. Element movements were free on the surface and fixed at the bottom plane. On the side faces, horizontal movements were fixed, and vertical movements were allowed. The soil bodies and reinforcement bodies were represented by meshes of 10node tetrahedral elements, providing second-order interpolation of displacements. The tunnel boring machine (TBM) shell, tunnel lining, and Liuzhou Road Interchange structures were represented by six-node plate elements. The railway tracks were represented by beam elements and fixed to the subgrade. The meshes were generated with a reference size of $1 \mathrm{~m}$ in soil and refined as $0.5 \mathrm{~m}$ in structures. The numerical simulation took $8 \mathrm{~h}$ on a workstation with $16 \mathrm{CPU}$ cores.

The hardening soil model proposed by Schanz et al. [15] was used to simulate the soil mass. The model contains the shear hardening and compression hardening behaviors of soft soil, and it was proven effective in similar adjacent construction projects in Shanghai by Wang et al. [16, 17]. The soil parameters for each soil layer were determined using the engineering geological investigation report from the study area in combination with the relevant technical suggestions provided by Wang et al. [16, 17]. For Shanghai soil layers $2,3,4$, and $5_{3}$, the literature provides relationships for determining the effective reference Young's modulus for unloading and reloading $E_{\mathrm{ur}}^{\text {ref }}$ and reference stiffness modulus corresponding to the reference confining pressure of $100 \mathrm{kPa}, E_{50}{ }^{\text {ref }}$, using the compression modulus $E_{s 0.1-0.2}$ in the geological investigation report.

During the construction of the existing Liuzhou Road Interchange, rotary jet grouting piles and mixing piles were used to reinforce the foundation. In Plaxis $3 \mathrm{D}$, the shield tunneling process was simulated by deactivating the soil volume elements and activating the TBM elements, applying the grouting and jacking pressure, applying area contraction, and applying face pressure within the tunnel, as in Brinkgreve et al. [18]. The complete construction process was simulated to examine staged excavation in line with the in situ advancing sequence and direction. Each calculation step consisted of the excavation surface reaching one pair of tracks. Staged construction simulates the ground loss caused by tunnel excavation according to the engineering properties of the tunnel and soil layer being crossed, line shape, and relevant engineering experience. Ground loss was simulated using the area contraction method with a contraction ratio of $0.4 \%$ based on local best practices for $6 \mathrm{~m}$ diameter shield tunneling and previously reported data $[19,20]$. In the FEM, tunneling with balanced chamber pressure was assumed such that the pressure on the excavation surface balances the static earth pressure.

The maximum settlement results for each turnout with and without grouting reinforcement as calculated by numerical simulation are shown in Table 4 . The results 
TABLE 2: Comparison of the proposed route schemes.

\begin{tabular}{|c|c|c|}
\hline Parameter & (East) Liuzhou Road scheme & (West) Guilin Road scheme \\
\hline Length $(\mathrm{km})$ & 3.46 & 2.91 \\
\hline Line shape & Poor, 2 curves with $R=350 \mathrm{~m}$ & Good, regular curve with $R<450 \mathrm{~m}$ \\
\hline Interchange transferability & Good & Poor \\
\hline Passenger appeal & Good & Poor \\
\hline $\begin{array}{l}\text { Impact of construction on road } \\
\text { traffic }\end{array}$ & Acceptable & Extensive \\
\hline Railway to be crossed & $\begin{array}{c}\text { East throat of the Shanghai South } \\
\text { Station }\end{array}$ & West throat of the Shanghai South Station \\
\hline Buildings to be crossed & 4 & 0 \\
\hline $\begin{array}{l}\text { Other underground structures to be } \\
\text { crossed }\end{array}$ & Liuzhou Road Interchange & $\begin{array}{c}\text { Guilin Road Interchange, tunnel section of the Metro Line } 1 \text { and } \\
\text { its diaphragm wall }\end{array}$ \\
\hline Engineering risk & High & Medium \\
\hline
\end{tabular}

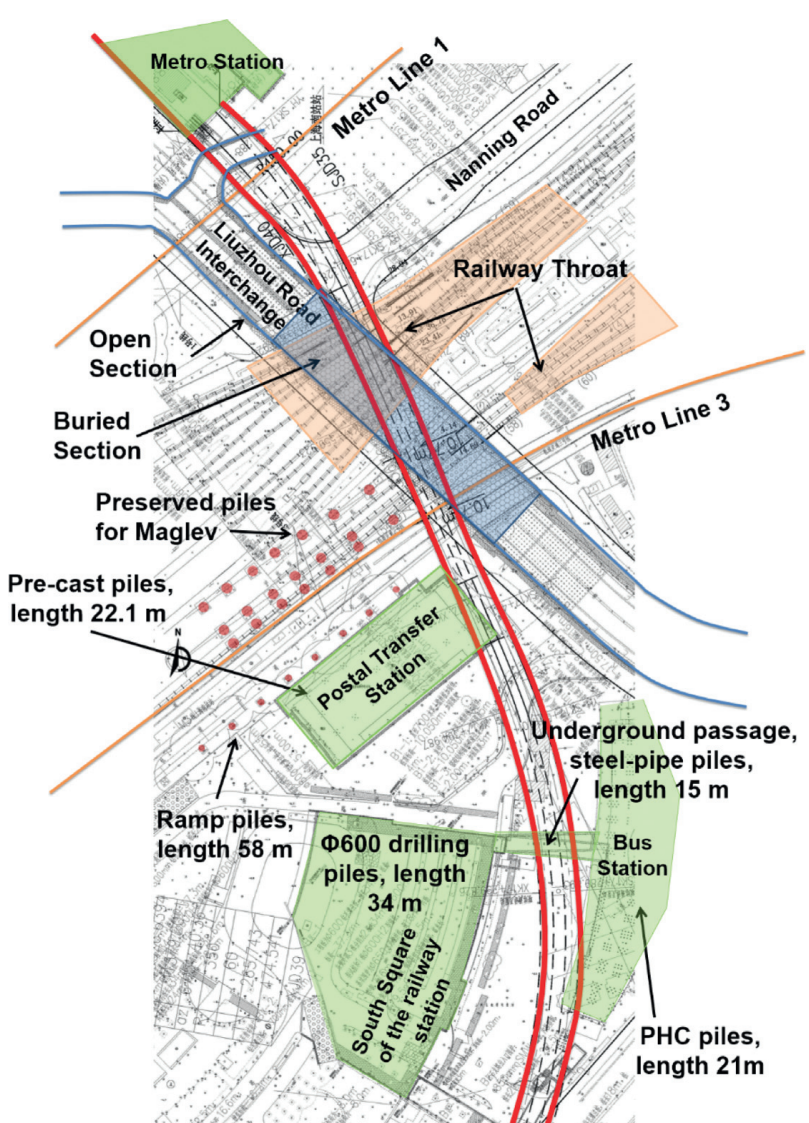

Figure 3: Plan view of the construction constraints and selected line alignment.

demonstrate that the maximum track settlement occurs after two tunnel advancement steps. The simulated displacement patterns in the station throat are essentially equivalent, for which the subsidence and height irregularity curve of Lane 7 are shown in Figures 6 and 7, respectively. Note that Lane 7 is the major track lane in the middle of the throat area of the station and is connected to the double-slip turnout.

Due to the high overall rigidity of Liuzhou Road Interchange, the calculated settlement pattern differs from conventional analytical solutions such as that in [21] or numerical simulations such as those of Chehade and
Shahrour [22] and Chakeri et al. [23]. The calculated maximum track settlement of $11.52 \mathrm{~mm}$ occurs at the intersection of Liuzhou Road Interchange with the east metro tunnel. Ground improvement under the turnout area on the east side of Liuzhou Road Interchange reduced the track deformation by approximately $32-35 \%$ in the numerical analysis. The maximum settlement after improvement was calculated to be $7.60 \mathrm{~mm}$. The height irregularity of a curve with $10 \mathrm{~m}$ chord length was also calculated; as shown in Figure 7, the maximum simulated height irregularity of each track is $0.82-0.9 \mathrm{~mm}$. Although the step at which the maximum irregularity occurs differs between the tracks, it typically occurs during shield tunneling under each track. The train speed in the throat area of this station is $35 \mathrm{~km} / \mathrm{h}$ in the turnouts, and the speed standard is $V_{\max } \leq 120 \mathrm{~km} / \mathrm{h}$ along the regular tracks. The allowable deviation of the gauge at the switch point is $\leq 1 \mathrm{~mm}$, and the permissible height irregularity is $\leq 4 \mathrm{~mm}$. Therefore, this design scheme is theoretically feasible.

3.3. Grouting Improvement. The strict deformation control standard and soft soil stratum render it necessary to provide grouting reinforcement under the railway subgrades. The numerical analysis demonstrates the effectiveness of the grouting design as described herein. As shown in Figure 8, the reinforcement zone is partitioned into areas $\mathrm{A}$ and B. Area A is adjacent to Liuzhou Road Interchange, and the vertical reinforcement range is $5-29 \mathrm{~m}$ below the railway, which is $1 \mathrm{~m}$ below the bottom of the tunnel (Figure 9). The reinforcement depth of area B is $5-20 \mathrm{~m}$ below the railway, which includes the relatively weak soft soil (layers 3 and 4 ) in Shanghai. The grouting spacing is $0.4 \mathrm{~m}$, and the unconfined compression strength of the reinforced soil exceeds $0.8 \mathrm{MPa}$.

The dense arrangement of equipment in the railway throat dramatically limits the construction area available for ground improvement. The "WSS" grouting technique, in which a double-tube grouting machine with nonshrink dualcomponent fluid is used, requires only a small space for operation of mechanical equipment and provides reliable reinforcement; thus, it was selected for this project. In the "WSS" method, the drilling machine, pump, and grouting slurry mixer are separate and connected by flexible tubes. During construction, once the drilling rig reaches the 
TABle 3: Comparison of line alignments.

\begin{tabular}{|c|c|c|c|}
\hline Item & Scheme 1 & Scheme 2 (selected) & Scheme 3 \\
\hline Minimum curve radius $(\mathrm{m})$ & 450 & 350 & 300 \\
\hline Line shape beneath railway throat & Curvature, $R=450 \mathrm{~m}$ & Straight line & Partly straight; partly curvature $R=300 \mathrm{~m}$ \\
\hline Tunneling difficulty & Average & Good & Poor \\
\hline Turnouts right above the tunnels & 6 & 3 & 3 \\
\hline Double-slip turnouts affected & 2 & 1 & 1 \\
\hline Spatial relationship & Reference & $9-11 \mathrm{~m}$ to the west & $12-15 \mathrm{~m}$ to the west \\
\hline Metro operation condition & Good & Average & Poor \\
\hline
\end{tabular}

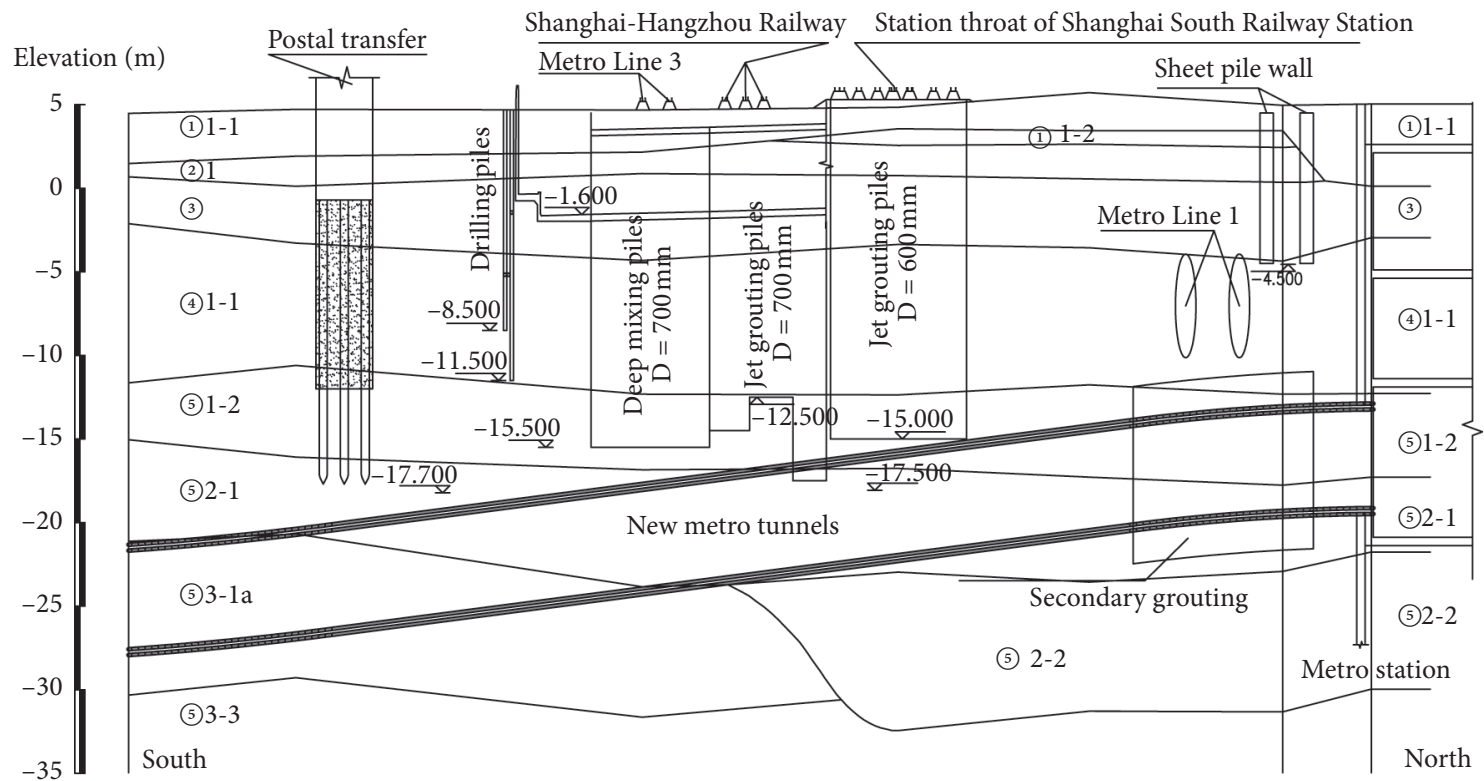

Figure 4: Profile of the selected line alignment scheme (scheme 2).

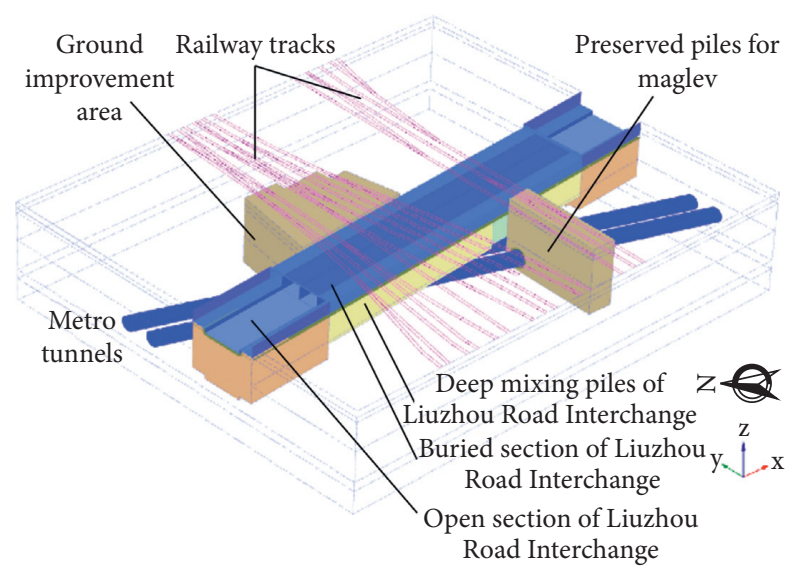

FIGURE 5: Proposed 3D finite element model (FEM).

predetermined depth, a simultaneous grouting machine mixes the two fluids and performs directional, quantitative, and constant pressure grouting using electronic monitoring.

3.4. Mechanical Optimization. In this project, a new earthpressure-balanced (EPB) shield machine with a moderate overexcavation capacity was selected for the sandy strata excavation in the tunnel. Furthermore, a series of modifiers was used to increase the subsidence control effects further. Specifically, the cutter head opening ratio was set to $40 \%$ and 16 thrust pump groups were used instead of 8 . An additional gate was also installed on the outlet of the screw conveyor, forming three-layer prevention for spew. Finally, the shield shell contained additional radial grouting holes as well as secondary grouting holes in the backups.

The segment design of the cross section was also adjusted to minimize subsidence. In the revised design, six tunnel segments are connected by bolts in a nonstaggered manner. Each of the standard, adjacent, and bottom blocks has two additional grouting holes to enhance the supplementary grouting effect. In addition, the simultaneous grouting is performed using a novel, patented, high-density singleliquid slurry. In this slurry, sand, fly ash, bentonite, hydrated lime, and admixtures are mixed with water to form a highdensity plastic single-liquid mortar with high shear capacity and low viscosity. The component ratio was optimized based on Zhou et al. [24]. Table 5 summarizes the composition of the grouting.

3.5. Preset of TBM Operation Parameters. An area $60 \mathrm{~m}$ ahead of the railway subgrades was set as a trial tunneling section. T 
TABLE 4: FEM simulation results with and without ground improvement.

\begin{tabular}{lcc}
\hline Position & \multicolumn{2}{c}{ Maximum settlement $(\mathrm{mm})$} \\
Unreinforced & ground & $\begin{array}{c}\text { Reinforced } \\
\text { ground }\end{array}$ \\
\hline Turnouts numbers & -11.41 & -7.39 \\
$51-57$ & -11.52 & -7.60 \\
Turnout number 63 & -11.11 & -7.40 \\
Turnout numbers & -10.94 & -7.39 \\
$77-83$ & \\
Turnout number 93 & & \\
\hline
\end{tabular}

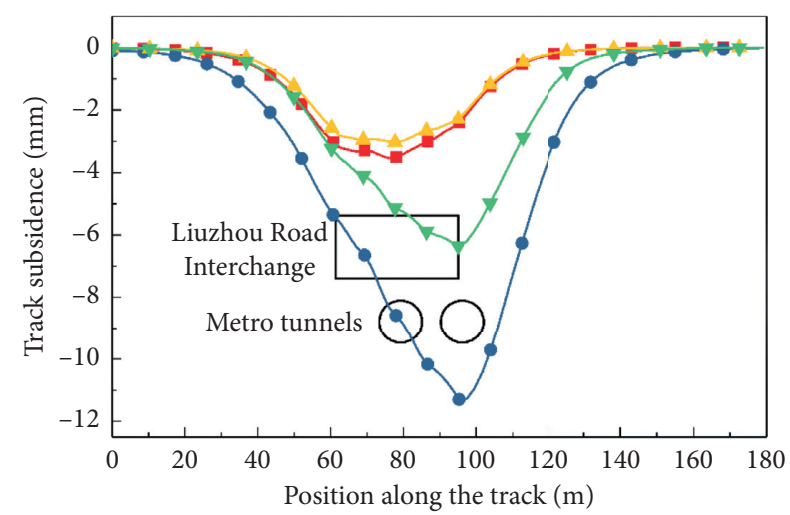

FEM simulation

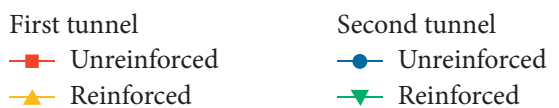

Figure 6: FEM simulation results.

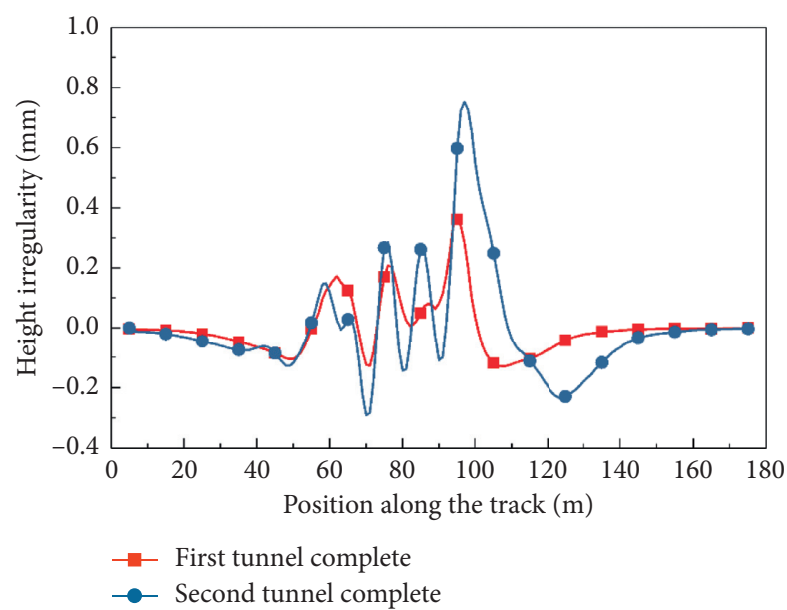

FIGURE 7: Simulated height irregularity of the track at different positions.

hree cross sections, each with nine ground subsidence monitoring points, were arranged at $20 \mathrm{~m}$ intervals in the trial section. Two of the three sections were equipped with tube settlement gauges. The trial section was predominantly used to collect information on the relationship between the earth pressure, machine advancing speed, excavated volume, grouting volume, grouting pressure, and ground settlement. Additional objectives were to explore the soil properties and to preview the soil displacement pattern resulting from driving the shield in this stratum. The experience gained from the trial tunneling section ensured that the construction parameters during shield tunneling across the railway would maintain the subsidence within the allowable variable range. Furthermore, simultaneous grouting was performed in line with the standards for dual control of grouting volume and pressure. By strictly controlling the construction quality and standardizing the construction procedures and parameters, the subgrade volume loss could be appropriately controlled.

3.6. Real-Time Monitoring. An automatic monitoring system was used to monitor the existing railway in the east throat of Shanghai South Railway Station in real time. Two fully automatic total stations with an angular accuracy of $0.5^{\prime \prime}$ were used to avoid single-point failure, and the instrument automatically searches for monitoring points in all weather conditions, reducing errors caused by human centering. Real-time data were collected to provide timely information regarding foundation improvement and helped with feedback control of the EPB machine. The monitoring content included the settlement and horizontal displacement of the track and subgrade shoulder, as well as the settlement, horizontal displacement, and inclination of the catenary column. Prism monitoring points were adopted to observe both horizontal and vertical displacements.

Shanghai South Railway Station has a ballasted track structure. The monitoring point layout was developed considering the characteristics of ballasted track, as well as the influence of monitoring equipment on operation. As shown in Figure 10, the observation points were spaced $10 \mathrm{~m}$ apart for each lane of tracks. The monitoring length reached $90 \mathrm{~m}$, which is determined by the influence zone of tunneling (see Figure 6). Due to the different lengths of improvement under each track, the monitoring points were arranged according to the actual situation on site. Each catenary column was mounted with two monitoring prisms spaced vertically by $\geq 2 \mathrm{~m}$.

Two observation piers supporting the total stations were installed on the roof of the second floor of the railway operation complex. Three prisms were arranged in the rearview direction of the observation pier as the rear-viewpoint within $100 \mathrm{~m}$ of the observation pier to monitor the stability of the observation site itself. The initial value of the monitoring data was collected one week before construction began. The maximum monitoring frequency was set as once per hour during grouting, since grouting in shallow soil causes immediate track displacements. The maximum monitoring frequency was once every $2 \mathrm{~h}$ during tunnel excavation, because the TBM typically advances 6 rings of lining per day, and each advancement contains thrusting forward and lining installation. The monitoring frequencies were adjusted with the different construction periods (see Table 6). 


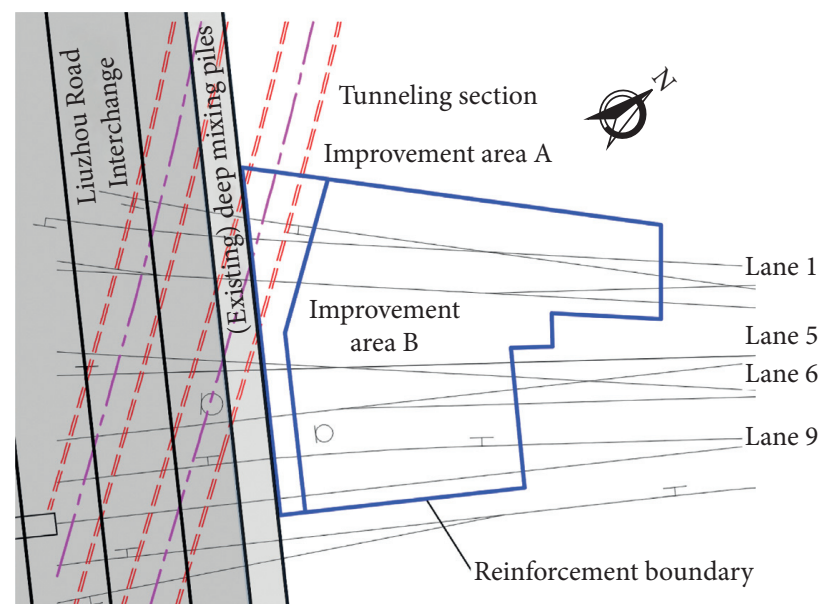

Figure 8: Plan view of the ground improvement areas.

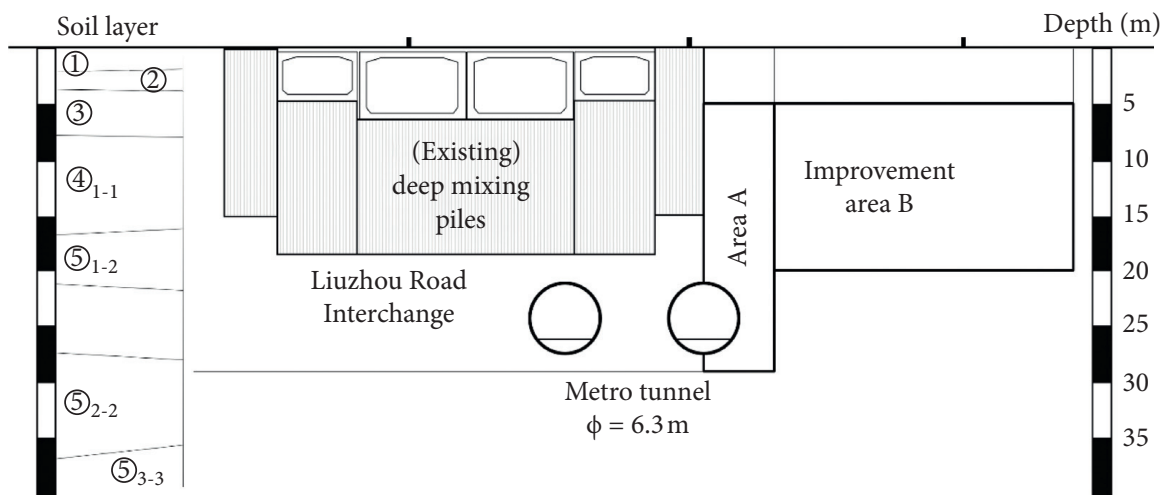

Figure 9: Cross-section view of the ground improvement areas.

TABLE 5: Material composition of tail-void grouting.

\begin{tabular}{lc}
\hline Item & Content $\left(\mathrm{kg} / \mathrm{m}^{3}\right)$ \\
\hline Sand & 1180 \\
Fly ash & 300 \\
Bentonite & 50 \\
Lime & 80 \\
Admixtures & 3 \\
Water & 285
\end{tabular}

Choosing the deformation control threshold for safely excavating a tunnel below railway turnouts is a significant and challenging problem for projects such as this one. In this project, the threshold value was selected according to "Measures for Safety Management of Public Works of Shanghai Railway Administration" [25] in conjunction with deformation monitoring requirements and engineering experience from similar projects involving shield tunneling beneath the railway (Table 7).

\section{Analysis}

Throughout the construction process, the monitoring instrument collected data effectively and consistently. As a result, we were able to determine that the implementation of the proposed project scheme achieved the desired results. To simplify the monitoring data, the displacement of Lane 7 was selected as a representative example for detailed analysis, since it is the major lane immediately above the tunnel sections.

The ground improvement stage took 1 month to complete and caused random ground movement within a maximum displacement of $4.5 \mathrm{~mm}$ (Figures 11(a) and 11(b)). Drilling the tubes merely caused track displacement, and the grouting in tubes induced most of the track displacement. The horizontal and vertical track displacements are in the same range, about $5 \mathrm{~mm}$. The displacement directions seem to be random, because of batched sequence of drilling and grouting and the stochastic grouting pressure induced by human factors. The grouting-induced soil displacement was not predicted in the FEM analysis but was controlled on site by engineering methods. Track displacement did not reach any single-day alert values at any point, and track geometry maintenance was scheduled after the reinforcement of the station throat.

Tunnel advancing began 45 days after the grouting was completed. The twin tunnels were constructed one after the other, taking 30 and 40 days to complete, respectively (Figures 12(a) and 12(b)). The first tunnel to the east caused an average track displacement of $2 \mathrm{~mm}$ and a maximum of 


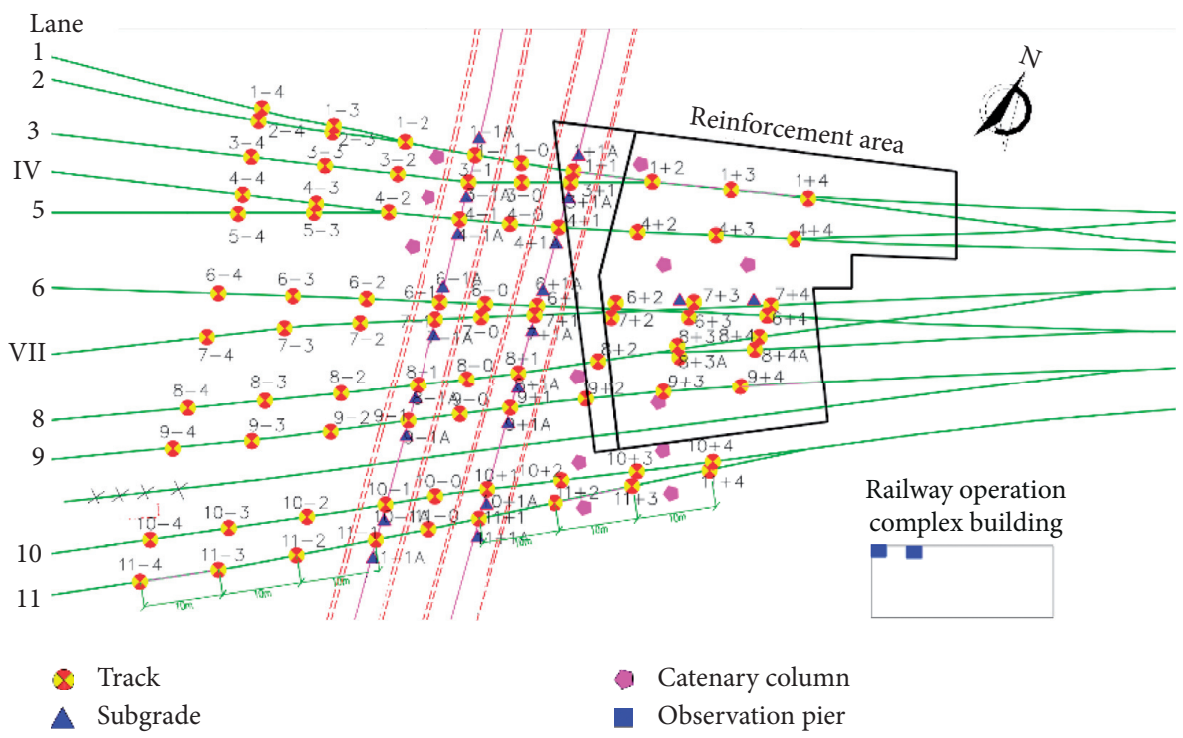

Figure 10: Planar view of the monitoring point layout.

TABLE 6: Monitoring frequency.

\begin{tabular}{lcc}
\hline Stage & Time period & Monitoring frequency (times per day) \\
\hline Grouting improvement & One week before improvement & 3 \\
Grouting improvement & During grouting & 24 \\
Improvement finished & One week & 1 \\
Tunneling & Crossing & 4 \\
Tunneling & $50 \mathrm{~m}$ before the cutter head reached the railway & 12 \\
Tunneling & One month & 4 \\
Tunneling finished & cutter tail left the railway & 1 \\
\hline
\end{tabular}

TABLe 7: Alert and threshold values for the monitoring data.

\begin{tabular}{lccc}
\hline Monitoring item & Vertical displacement $(\mathrm{mm})$ & Horizontal displacement $(\mathrm{mm})$ & Inclination of catenary column $(\%)$ \\
\hline Alert (single day) & \pm 1.6 & \pm 1.6 & 0.08 \\
Threshold (single day) & \pm 2 & \pm 2 & 0.10 \\
Threshold (cumulative) & \pm 10 & \pm 10 & 0.50 \\
\hline
\end{tabular}

$4.0 \mathrm{~mm}$; the uneven horizontal displacement was no greater than $5 \mathrm{~mm}$. The second tunnel advancement induced a larger disturbance in the soft soil stratum, with a maximum displacement of $8.4 \mathrm{~mm}$ and subsequent uneven settlement along each track. Due to the ground improvement and datadriven construction, the displacement never exceeded the threshold. Within 1 month of construction completion, the subgrade settlement largely stabilized, excluding some areas with persistent subsidence $[9,26]$. The catenary columns are less sensitive to vertical displacement than they are to the horizontal displacement induced by ground improvement and tunnel advancement. The maximum cumulative vertical displacement was $3.7 \mathrm{~mm}$, but the maximum horizontal displacement reached $5.0 \mathrm{~mm}$.

The settlement pattern of each tunneling stage could not be clearly determined, in contrast to the results obtained through lab tests or in situ monitoring, such as those of Chapman et al. [27], Chen et al. [28], and Fang et al. [29].
Comparing the monitoring results to the numerical simulation results presented in this paper (Figure 6 and Table 4), the maximum settlements of each tunnel stage were predicted with acceptable error, but the dispersive nature of the displacement at different positions was not well predicted. This finding also indicates that the simulated track irregularity may not be appropriate for on-site situations; therefore, on-site monitoring of the track irregularity and turnout geometry is necessary. After on-site inspection, the track structure deformation was deemed to satisfy the various required control criteria. Thus, the tunneling project was determined to have successfully achieved the goal of the crossing of a complex throat area consisting of 11 lanes.

\section{Experience Gained from the Project}

5.1. Lessons from the Detailed Design Processes. A complex tunneling project cannot be completed successfully without 

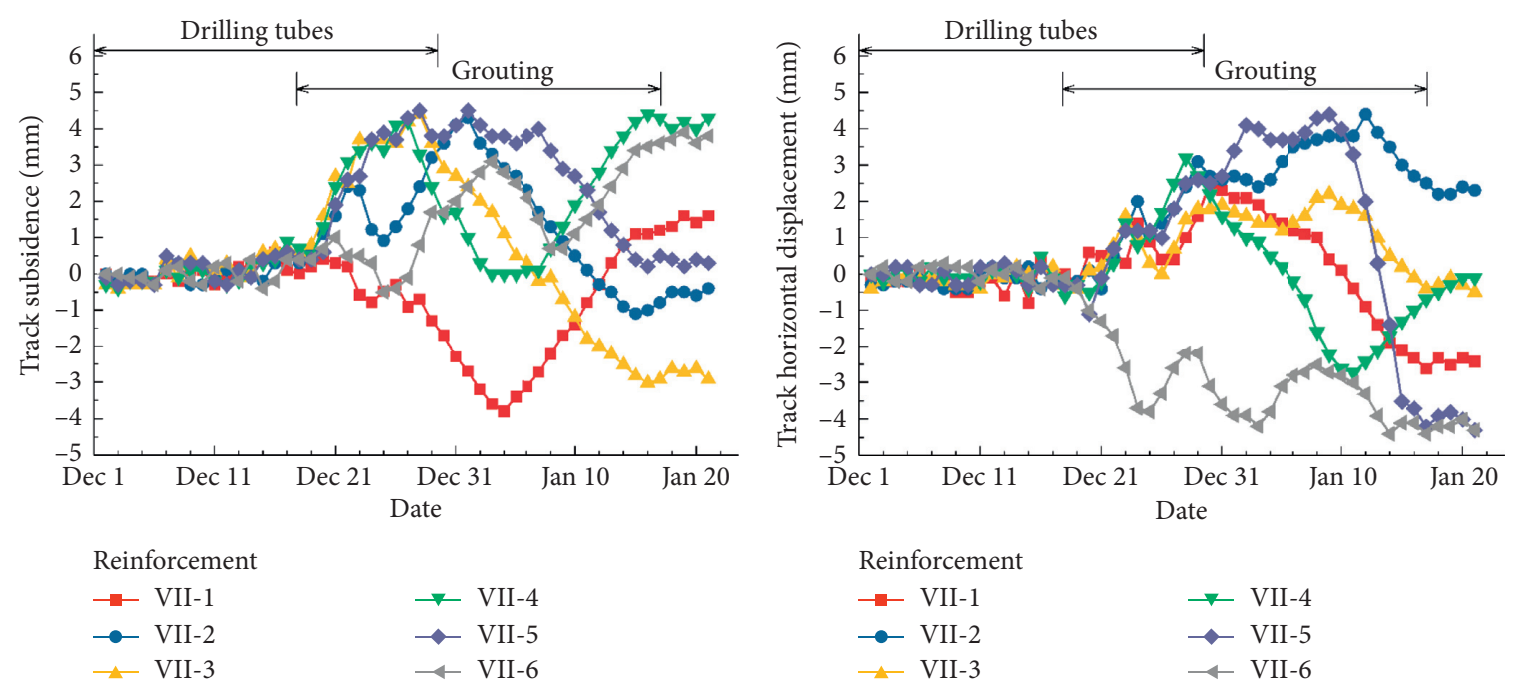

(a)

(b)

Figure 11: Monitored track displacement during ground improvement. (a) Track subsidence. (b) Horizontal track displacement.

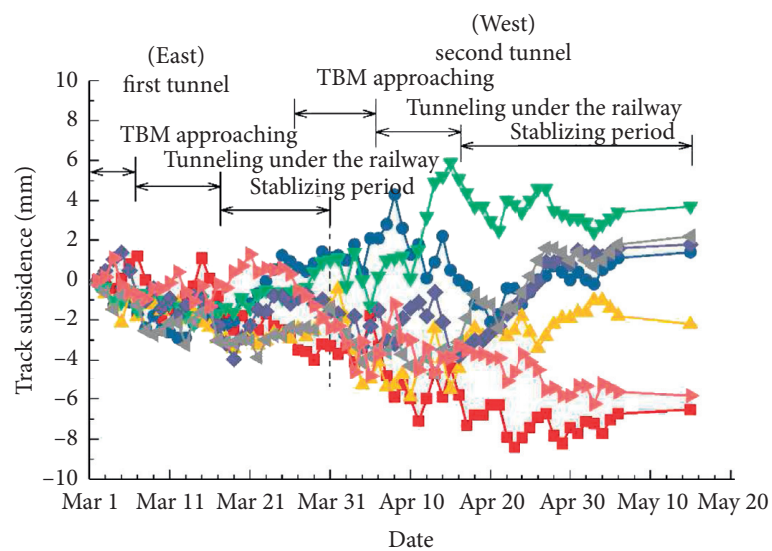

Tunneling
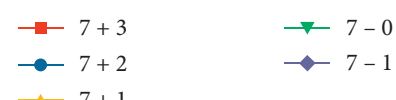

(a)

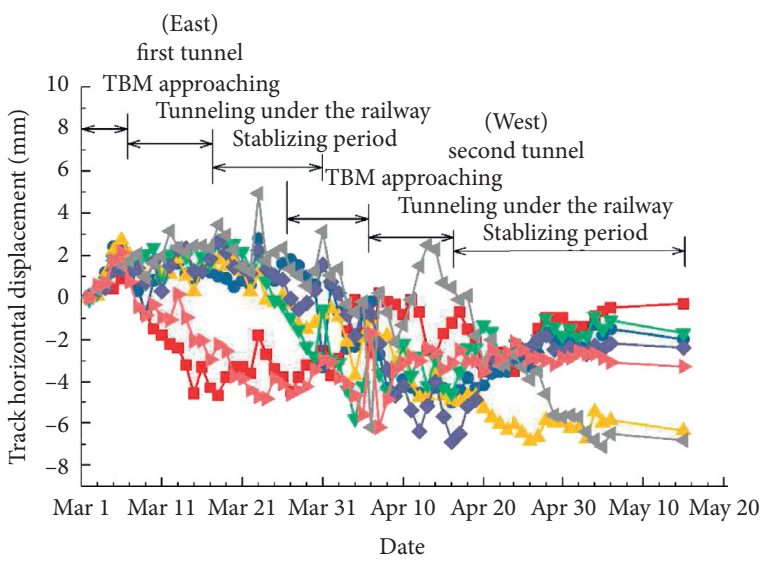

Tunneling
$-7+3$
$-7+2$
$-7+1$
$-7-2$

$\rightarrow 7-1$

$\rightarrow-7-3$

(b)

FIGURE 12: Monitored track displacement during tunnel advancement. (a) Track subsidence. (b) Horizontal track displacement.

detailed planning. Detailed route schematics, structure designs, construction plans, and monitoring programs are essential elements of railway turnout undercrossing projects that must be developed prior to beginning construction. The careful execution of each plan by the relevant professional organization(s) is also necessary.

In developing the detailed designs, the location of the metro station and the metro line alignments should be rigorously compared and selected. It is necessary to determine all constraints that could affect the construction of new tunnels, including the hydrogeological conditions, foundation improvement measures of the nearby railway lines/ stations and other buildings, layout of the railway throat area, and usage of the railway arrival and departure lines and throat areas. This assessment is necessary for comprehensive evaluation of the influence of the proposed line alignment scheme on the nearby railway turnouts and the tip rails, which is important in determining the engineering feasibility of the project and the ability to facilitate passenger transfer between lines. It is also often necessary to reinforce the foundation of the railway subgrade when such projects are proposed for soft soil areas. Thus, the design and step-bystep plan for ground improvement construction should also be defined well in advance.

Due to the complex structures and irregular spatial relationships in the railway throat, the conventional plane 
strain method and empirical formula have considerable limitations with regards to calculating surface settlement. Thus, 3D FEM analysis is needed to estimate the track displacement and irregularities during construction. The influence of ground improvement and shield construction should also be estimated by the FEM, and the design scheme should be adjusted based on the predicted deformation rate if necessary.

The construction and monitoring plan should be as detailed and coordinated as possible. A reasonably selected crossing period may decrease the number of passenger railway trains affected by construction of the underlying tunnels. For example, implementing appropriate speed limit measures in the throat area in conjunction with the railway department and arranging the construction and maintenance times to be overnight or during low-traffic periods may minimize the impact of construction. In addition, construction should be planned such that the trial and track sections are in the same stratum wherever possible. If ground improvement is required for safe construction in the relevant stratum, the grouting points, mechanical, and site arrangements may need to be planned to meet railway requirements. The schedules and spatial arrangement of each stage of preparation and construction should thus be determined in detail ahead of time and reached in consensus with railway operation institutions.

Finally, the monitoring scheme design must be consistent with the potential range of surface settlement resulting from construction, and intensive monitoring is required during ground improvement and shield tunneling. The monitoring plan requires cooperative management, a procedure for information feedback to relevant institutions, and a multiparty coordinated emergency plan, which should all be determined prior to initiating construction.

\subsection{Construction Machinery Maintenance and Optimized} Operation. It is necessary to ensure that all construction machinery is effectively maintained and operated accurately to reduce uncertainty in construction and ensure conformance with the detailed plans for the project. In this case, shield equipment, simultaneous grouting, secondary grouting, and other types of equipment were thoroughly inspected before construction and carefully maintained during construction to ensure that the shield entered the crossing area in optimal conditions.

Various monitoring measures were adopted to ensure the accuracy of the data. The angular precision of the surface displacement observation was increased to $1^{\prime \prime}$. The shield machine was mainly operated in accordance with the automatic monitoring data provided by the static and electric level meters; however, supplementary manual observations were still necessary. Before the implementation of shield tunneling under the throat of the railway station, the data from the trial section were carefully analyzed. The deformation pattern of the soil body, chamber pressure, thrusting velocity, volume of excavated soil, amounts of simultaneous and secondary grouting, and grouting pressure were carefully optimized to ensure that the shield machine was appropriately positioned to enter the crossing section.

5.3. Multiparty Cooperation. Multiparty cooperation was necessary to achieve the top project priority-engineering safety-in tunneling across the turnout area. In coordinating the construction plan, the design firm and railway administration jointly participated in the research on the influence of the station and subway track plan on the passenger railway system, including the possibility of adjusting throat equipment, allowed velocity of trains passing through the switches, and overall operating conditions in the station throat. FEM analysis confirmed the feasibility of the construction plan with regard to its potential influence on the overlying track structures. Joint arrangement of multiple parties was also used to determine the deformation control requirements and the feasibility of the detailed construction plan.

The shield construction monitoring unit and track engineering department of the relevant railway institutions maintained close communication throughout the project. Before construction, they reached a detailed consensus regarding the permissible railway status, including the track irregularity and railway subsidence in each region of the crossing section. The relevant parties coordinated to determine an appropriate layout of monitoring points, and the data were assessed by both parties to ensure the accuracy of the railway settlement measurements.

All parties involved in the project established coordinated data submission, alarm, and emergency response plans, as well as personnel organizations. Under normal circumstances, monitoring data automatically reaches contacts of the construction crew and supervisors, railway operator, track engineering department, consulting company, and other relevant institutions once per day online. A paper version of the data is also submitted and archived. If the alarm threshold is breached, the construction crew is immediately orally notified to suspend construction and review the alarm data urgently. After reviewing the data, all construction parties and equipment management units are immediately notified and the alarm data are submitted in writing. A monitoring and alarm analysis team was set up in advance to make decisions regarding the termination or continuation of construction based on response to certain data. Before crossing the railway station throat, all construction personnel were organized to study an exclusive technical disclosure manual, and the meeting and content were recorded in writing and archived.

\section{Conclusions}

This paper presented a case study of the safe implementation of a project for tunneling Shanghai Metro Line 15 under the railway throat of the Shanghai South Railway Station. A set of technical measures and management systems was generated for similar projects involving shield tunnel crossing beneath railway throats in soft soil strata. The major conclusions of this study are as follows: 
(1) Identifying all constraints in the project area facilitates the design of an effective scheme. The new scheme along Liuzhou Road and the detailed line alignment design balanced the ease of passenger flow between the metro station and passenger railway station, reducing the impact of tunnel construction on railway operation. The joint work of multiple parties, including the railway operation administration, the track engineering department, metro design teams, and construction, survey, and consulting companies, resulted in a consensus being reached on the design scheme and track displacement threshold of $2 \mathrm{~mm}$ within a single day.

(2) 3D FEM models were used to effectively calculate the impacted area and extent for the complicated terrain. The numerical results showed that ground improvement could reduce the track deformation during tunneling by $32 \%$, with a calculated maximum settlement of $7.6 \mathrm{~mm}$. The estimated track height irregularity at the double-slip turnout was $0.9 \mathrm{~mm}$, which demonstrated the feasibility of the proposed construction scheme.

(3) The disturbance of grouting was not inherently available in the numerical simulation but was controlled by in situ monitoring feedback. The "WSS" grouting technique satisfied the need for a compact operation area between the tracks and minimized randomly distributed ground movement to at most $4.5 \mathrm{~mm}$.

(4) The EPB shield machine and tunnel segment cross sections were optimized to be in the soft but sandy and water-confining strata around the tunnel. The use of additional thrust pumps and grouting holes, a third gate on the screw conveyor, and an optimized slurry composition allowed better control of subsidence effects and increased safety reserves. A $60 \mathrm{~m}$ trial section ahead of the tunnel was used to identify appropriate construction parameters for the section crossing under the passenger railway tracks.

(5) Two fully automatic total stations for monitoring with enhanced angular accuracy of $0.5^{\prime \prime}$ were used to avoid single-point failure of the monitoring system. The automatic monitoring system collected data consistently and ensured that the information needed for safe construction was available. Multiparty coordinated data submission and alarm and emergency response plans were also established prior to construction.

(6) The proposed project scheme was implemented with the desired results; the twin tunnels under the railway throat area exhibited a maximum track displacement of $8.4 \mathrm{~mm}$, which satisfied the safety threshold values.

We believe that the experience and techniques developed in this project are extremely significant for ongoing research with respect to the shield tunneling method. This report is a valuable addition to the existing literature and can serve as a reference for similar future projects. If the randomness of soil properties and stochastic features in engineering can be developed further, construction assessment can be more directive. In addition, the engineering measures can be determined with more confidence according to different site conditions.

\section{Data Availability}

The numerical models and data used to support the findings of this study are available from the corresponding author upon request.

\section{Conflicts of Interest}

The authors declare that there are no conflicts of interest regarding the publication of this paper.

\section{Acknowledgments}

The authors gratefully acknowledge the engineers and technical staff of Shanghai Donghua Local Railway Development Co., Ltd., for their field monitoring efforts, as well as Shanghai TongJi Engineering Consulting Co., Ltd., for their assistance during this study. Financial support for this research was provided by the National Natural Science Foundation of China (NSFC) through Grant nos. 51778485 and 51608384 .

\section{References}

[1] J. S. Huo, B. L. Wang, and S. H. Zhou, "Safety analysis of foundation reinforcement scheme for shield tunnel underpassing intercity railway," China Railway Science, vol. 32, no. 5, pp. 71-77, 2011, in Chinese.

[2] Z. L. Chen, J. Y. Chen, H. Liu, and Z. F. Zhang, "Present status and development trends of underground space in Chinese cities: evaluation and analysis," Tunnelling and Underground Space Technology, vol. 71, no. 1, pp. 253-270, 2018.

[3] H. Yuan, Y. He, and Y. Wu, "A comparative study on urban underground space planning system between China and Japan," Sustainable Cities and Society, vol. 48, Article ID 101541, 2019.

[4] Standards of China Rail, Railway Line Repair Rules, Tieyun, vol. 146, China Railway Publishing House, Beijing, China, 2006, in Chinese.

[5] R. J. Cai, "The study of large scale passenger railway station's throat carrying capacity," Master thesis, Lanzhou Jiaotong University, Lanzhou, China, 2014.

[6] K. M. Lee, H. W. Ji, C. K. Shen, J. H. Liu, and T. H. Bai, "Ground response to the construction of Shanghai metro tunnel-line 2," Soils and Foundations, vol. 39, no. 3, pp. 113-134, 1999.

[7] C. W. W. Ng, G. B. Liu, and Q. Li, "Investigation of the longterm tunnel settlement mechanisms of the first metro line in Shanghai," Canadian Geotechnical Journal, vol. 50, no. 6, pp. 674-684, 2013.

[8] G. L. Ye, T. Hashimoto, S. L. Shen, H. H. Zhu, and T. H. Bai, "Lessons learnt from unusual ground settlement during Double-O-Tube tunnelling in soft ground," Tunnelling and Underground Space Technology, vol. 49, pp. 79-91, 2015. 
[9] H. N. Wu, S. L. Shen, and J. Yang, "Identification of tunnel settlement caused by land subsidence in soft deposit of Shanghai," Journal of Performance of Constructed Facilities, vol. 31, no. 6, Article ID 04017092, 2017.

[10] S. Zhou, J. Xiao, H. Di, and Y. Zhu, "Differential settlement remediation for new shield metro tunnel in soft soils using corrective grouting method: case study," Canadian Geotechnical Journal, vol. 55, no. 12, pp. 1877-1887, 2018.

[11] H. L. Zhu, X. H. Zhang, X. W. Yang, and S. H. Zhou, "Effect of subway operation load on cross-section deformation of largediameter shield tunnel," in Proceedings of the CICTP 2014: Safe, Smart, and Sustainable Multimodal Transportation Systems, pp. 1248-1258, Changsha, China, 2014.

[12] Shanghai Municipal Planning and Natural Resources Bureau, "Publicity of the Special Plan (Draft) for Rail Transit Line 15," 2014, http:/ghzyj.sh.gov.cn/hdpt/gzcy/sj/201406/t20140623_ 630065.htmlin Chinese.

[13] D. Huang and B. Zeng, "Influence of double-O-tube shield rolling on soil deformation during tunneling," International Journal of Geomechanics, vol. 17, no. 11, Article ID 04017105 , 2017.

[14] D.-J. Ren, S.-L. Shen, A. Arulrajah, and H.-N. Wu, "Evaluation of ground loss ratio with moving trajectories induced in double-O-tube (DOT) tunnelling," Canadian Geotechnical Journal, vol. 55, no. 6, pp. 894-902, 2018.

[15] T. Schanz, P. A. Vermeer, and P. G. Bonnier, "The Hardening Soil Model: Formulation and Verification”. Beyond 2000 in Computational Geotechnics, Taylor \& Francis Group, London, England, 1999.

[16] W. D. Wang, H. R. Wang, and Z. H. Xu, "Experimental study of parameters of hardening soil model for numerical analysis of excavations of foundation pits," Rock and Soil Mechanics, vol. 33, no. 8, pp. 2283-2290, 2012, in Chinese.

[17] W. D. Wang, H. R. Wang, and Z. H. Xu, "Study of parameters of HS-Small model used in numerical analysis of excavations in Shanghai area," Rock and Soil Mechanics, vol. 34, no. 6, pp. 1766-1774, 2013, in Chinese.

[18] R. B. J. Brinkgreve, E. Engin, and W. M. Swolfs, Plaxis 3D 2012 Manual, Plaxis bv, Delft, Netherlands, 2012.

[19] S. M. Liao, J. H. Liu, R. L. Wang, and Z. M. Li, "Shield tunneling and environment protection in Shanghai soft ground," Tunnelling and Underground Space Technology, vol. 24, no. 4, pp. 454-465, 2009.

[20] C. Liu, Z. X. Zhang, and R. A. Regueiro, "Pile and pile group response to tunnelling using a large diameter slurry shield - case study in Shanghai," Computers and Geotechnics, vol. 59, no. 1, pp. 21-43, 2014.

[21] P. B. Peck, "Deep excavations and tunneling in soft ground," in Proceedings of the 7th International Conference on Soil Mechanics and Foundation Engineering, Sociedad Mexicana de Mecanica de Suelos AC, Mexico City, Mexico, pp. 225-290, 1969.

[22] F. H. Chehade and I. Shahrour, "Numerical analysis of the interaction between twin-tunnels: influence of the relative position and construction procedure," Tunnelling and Underground Space Technology, vol. 23, no. 2, pp. 210-214, 2008.

[23] H. Chakeri, Y. Ozcelik, and B. Unver, "Investigation of ground surface settlement in twin tunnels driven with EPBM in urban area," Arabian Journal of Geosciences, vol. 8, no. 9, pp. 7655-7666, 2015.

[24] S. H. Zhou, X. H. Zhang, D. Wu, and H. G. Di, "Mathematical modeling of slurry infiltration and particle dispersion in saturated sand," Transport in Porous Media, vol. 124, no. 1, pp. 91-116, 2018.
[25] S. T. Gong, "Measures for Safety Management of Track Maintenance of Shanghai Railway Administration," no. 382, Shanghai Railway Administration, Ningbo, China, 2017.

[26] S. H. Zhou, H. G. Di, J. H. Xiao, and P. X. Wang, "Differential settlement and induced structural damage in a cut-and-cover subway tunnel in a soft deposit," Journal of Performance of Constructed Facilities, ASCE, vol. 30, no. 5, Article ID 04016028, 2016.

[27] D. N. Chapman, S. K. Ahn, and D. V. Hunt, "Investigating ground movements caused by the construction of multiple tunnels in soft ground using laboratory model tests," Canadian Geotechnical Journal, vol. 44, no. 6, pp. 631-643, 2007.

[28] R. P. Chen, J. Zhu, W. Liu, and X. W. Tang, "Ground movement induced by parallel EPB tunnels in silty soils," Tunnelling and Underground Space Technology, vol. 26, no. 1, pp. 163-171, 2011.

[29] Y. Fang, C. He, A. Nazem, Z. Yao, and J. Grasmick, "Surface settlement prediction for EPB shield tunneling in sandy ground," KSCE Journal of Civil Engineering, vol. 21, no. 7, pp. 2908-2918, 2017. 